\title{
Selectivity issues in the catalytic multiphase reduction of functionalized halogenated aromatics over Pd/C, Pt/C, and Raney-Ni
}

\author{
Galina Evdokimova $^{\mathrm{a}, 1}$, Sergei Zinovyev ${ }^{\mathrm{a}}$, Alvise Perosa ${ }^{\mathrm{a}}$, Pietro Tundo ${ }^{\mathrm{b}, *}$ \\ a Interuniversity Consortium "Chemistry for the Environment" (INCA), Dorsoduro 2137, 30123 Venezia, Italy \\ b Dipartimento di Scienze Ambientali, Ca' Foscari University of Venice, Dorsoduro 2137, 30123 Venezia, Italy
}

Received 10 December 2003; received in revised form 27 January 2004; accepted 30 January 2004

\begin{abstract}
The multiphase system, consisting of a biphasic isooctane-aqueous medium, a heterogeneous catalyst, and a quaternary ammonium salt (Aliquat 336) — a supported ionic liquid catalyst surface modifier-allows efficient hydrodehalogenation under mild conditions $\left(50{ }^{\circ} \mathrm{C}\right.$ and $1 \mathrm{~atm} \mathrm{H}_{2}$ ). In the reactions of various halogenated benzenes, nitrobenzene, benzonitrile, benzaldehyde in the multiphase catalytic system, the selectivity of reduction of certain groups (hydrodehalogenation, carbonyl hydrogenation, hydroxyl hydrogenolysis, aromatic reduction) is a function of the presence of a phase-transfer agent, $\mathrm{pH}$ of the aqueous phase, catalyst choice $(5 \% \mathrm{Pd} / \mathrm{C}, 5 \% \mathrm{Pt} / \mathrm{C}$ or $\mathrm{Raney}-\mathrm{Ni})$. The suggested mode of action of the quaternary salt involves the formation of a distinct ionic liquid layer at the catalyst-solution interface, where the reaction proceeds with alternative selectivity.
\end{abstract}

(C) 2004 Elsevier B.V. All rights reserved.

Keywords: Hydrodehalogenation; Selectivity; Multiphase system; Supported ionic liquid; Pd/C; Pt/C; Raney-Ni

\section{Introduction}

Interest for the hydrodehalogenation reaction, i.e. the substitution of a halogen atom with hydrogen, accompanied by the formation of the corresponding hydrohalic acid, i.e.

$$
\mathrm{Ar}-\mathrm{X}+\mathrm{H}_{2} \rightarrow \mathrm{Ar}-\mathrm{H}+\mathrm{HX} \text { or } \mathrm{RX}+\mathrm{H}_{2} \rightarrow \mathrm{R}-\mathrm{H}+\mathrm{HX}
$$

has grown over the past years in view of its potential to address the problem of utilization of aromatic halogenated compounds which represent an environmental and toxicological hazard. One of the advantages of hydrodehalogenation is that it is a reductive approach, which intrinsically eliminates the danger common to oxidative methods (including in particular incineration), i.e. the production of more toxic compounds (e.g. PCDD/Fs-polychlorinated dibenzo- $p$-dioxins and dibenzofurans) during the process [1-3]. Hydrodehalogenation can be carried out at high tem-

\footnotetext{
* Corresponding author. Tel.: +39-041-234-8642; fax: +39-041-234-8620.

E-mail address: tundop@unive.it (P. Tundo).

1 On leave from N.D. Zelinsky Institute of Organic Chemistry of Russian Academy of Sciences, Leninsky pr. 47, Moscow 119991, Russia.
}

peratures and pressures, often in the gas phase, using high pressure or in continuous flow [4-6]; alternatively the liquid systems (usually with alcohols) can be used to take advantage of the better solubility of hydrogen in polar solvents [7-10]. However, such systems suffer from very harsh reaction conditions and, connected to this low reaction selectivity, also concerning the reduction of different functional groups present in the same molecule. A few recent reports on hydrodehalogenation of halogenated aromatics under mild conditions describe the following catalytic systems: $\mathrm{Pt} / \gamma-\mathrm{Al}_{2} \mathrm{O}_{3}$ [11], $\mathrm{Pd} / \mathrm{C}-\mathrm{Et}_{3} \mathrm{~N}[12,13], \mathrm{Pd} / \mathrm{C}-\mathrm{H}_{2} \mathrm{NNH}_{2} \cdot \mathrm{HCl}$ $[14,15], \mathrm{Pd} / \mathrm{AlPO}_{4}-\mathrm{SiO}_{2}$ [16], hydrogen transfer using supported $\mathrm{Pd}$ [17], $\mathrm{Pd}-\mathrm{Ni} / \mathrm{C}$ [18].

Our recent findings have shown that a variety of reduction reactions can be carried out under mild conditions (generally $50^{\circ} \mathrm{C}$ and atmospheric pressure of hydrogen) in the multiphase catalytic system, consisting of a biphasic isooctane-aqueous medium and a heterogeneous catalyst, e.g. Pd/C [19-22], Pt/C [23-25] or Raney-Ni [26,27]. This system affords efficient and quantitative removal of aromatic chlorine, also in polychlorinated substances, which becomes possible in the presence of a quaternary ammonium salt and basic $\mathrm{pH}$ with $\mathrm{Pd} / \mathrm{C}$ or Raney-Ni. Normally, 


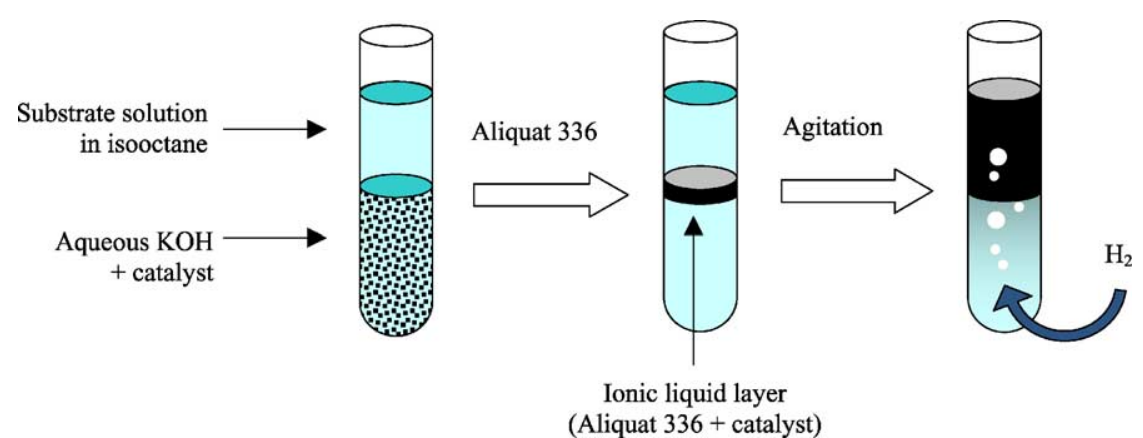

Scheme 1. Multiphase environment effect of Aliquat 336 as of supported ionic liquid.

the phase-transfer agents or surfactants, such as various quaternary ammonium salts or PEGs, Brij, etc. (less efficient) $[21,23,24,26]$, act as promoters, most commonly used is Aliquat 336 (tricaprylmethylammonium chloride), the well-known phase-transfer agent. Previously we have reported on the applications of this system with $\mathrm{Pd} / \mathrm{C}$ and Raney-Ni for the rapid and exhaustive dechlorination of a number of polychlorinated toxicants, such as PCBs [21], dioxins [28], lindane [29], etc.

The effects produced by the quaternary salt in the multiphase system can be ascribed to a formation by the latter of an ionic environment on the catalyst surface where the reaction proceeds [30] (see Scheme 1). As our previous results suggest, the role of Aliquat 336 in the system, rather than possible colloidal effects, seems to be coordination of the substrate in a certain way on the surface or surface modification, which renders it more reactive. Besides the hydrodehalogenation reaction, a number of other processes can benefit from this new environment. The effect by the quaternary salt can be different on different group reduction; whereas promoting reduction of the ones, the others can appear less reactive or not reactive at all. Owing to this, the multiphase system represents a tool, which often allows changing the selectivity (chemo and regio) of reduction of polyfunctionalized substrates. Another variable in defining reactivity of different groups and, therefore, the final selectivity of the reaction appears to be the $\mathrm{pH}$ of the aqueous phase; whereas some reactions, like hydrodechlorination, require the basic medium, the reduction of others can be more favored under neutral or acidic conditions.

We have reported previously on the selectivity of reduction of $p$-chloroacetophenone [25,27] and of some other (halogenated) aromatic ketones [22-24] under the multiphase conditions with $\mathrm{Pd} / \mathrm{C}$ and $\mathrm{Pt} / \mathrm{C}$. It has been shown that the products, such as dehalogenated ketone, or the corresponding phenyl or cyclohexyl alcohols, as well as phenyl or cyclohexyl hydrocarbons can all be obtained selectively, given the right system composition.

This paper describes and expands some of the issues related to the selectivity achievable in the hydrodehalogenation and reduction with the multiphase system. The number of polyfunctional substrates is extended to the ones having also nitro, nitrile, and aldehyde functions, namely p-chlorinated benzaldehyde, benzonitrile, and nitrobenzene, whose reduction is studied over the commonly used commercial 5\% $\mathrm{Pd} / \mathrm{C}$ and 5\% $\mathrm{Pt} / \mathrm{C}$. An objective is to explore the regioselectivity of hydrodechlorination versus reduction of the other group, and to see if and how the presence of Aliquat 336 in the biphasic system affects reactivity of these functions and brings changes to selectivity. Reaction of trans-chalcone has been chosen as another model to estimate the selectivity of the double bond versus carbonyl group reductions. In addition, the selectivity of reduction of different halogens and their types in polyhalobenzenes, e.g. 2-chloro-1-fluoro-4-iodobenzene, $p$-bromochlorobenzene, p-bromobenzylbromide, and others are discussed.

Considerations on the selectivity of reduction of different functions in different catalytic systems can shed light on the nature and particularities of substrate adsorption/coordination on the catalyst active site, as the diverse sequences of reduction of different functions can be indicative of the coordination of the substrate to the active site with one or another group. The presence of promoters, such as Aliquat 336, is important since these can affect the adsorption of the substrate and render one or another group more or less reactive.

\section{Experimental}

All the reagents and solvents were ACS grade and were used without further purification. $5 \% \mathrm{Pd} / \mathrm{C}$ was from Aldrich, Art. No. 20568-0.5\% Pt/C was from Fluka, Art. No. 80982. Raney-Ni (Actimet $\mathrm{M}^{\mathrm{TM}} 50 \%$ slurry in water) was from Engelhard $(93 \% \mathrm{Ni}$ and $7 \% \mathrm{Al}$, particle size distribution of $0-80 \mu \mathrm{m}$, surface area of $70-80 \mathrm{~m}^{2} / \mathrm{g}$ ). Aliquat $336^{\circledR}$ (tricaprylmethylammonium chloride) was from Aldrich, Art. No. 20561-3. GC analyses were performed on a Varian 3400 using a fused silica capillary column "Chrompack CP-Sil 24 CB lowbleed/MS" (30 $\mathrm{m} \times 0.25 \mathrm{~mm}$, film thickness $0.25 \mu \mathrm{m})$. GC/MS analyses were performed on an Agilent 5976 mass detector coupled to an Agilent $6890 \mathrm{~N}$ GC with an HP-5MS capillary column $(30 \mathrm{~m} \times 0.25 \mathrm{~mm}$, film thickness $0.25 \mu \mathrm{m})$.

The reactions were run in a $25 \mathrm{~mL}$ three-necked round-bottomed reactor with a water jacket, supplied with a 
tube for hydrogen supply, a water-jacketed condenser, stirred magnetically at $1000 \mathrm{rpm}$ and thermostated at $50 \pm 1{ }^{\circ} \mathrm{C}$. Generally, the reaction was started with $10 \mathrm{~mL}$ solution in isooctane of the corresponding substrate $(0.7 \mathrm{mmol})$, $n$-decane or $n$-dodecane $(0.35 \mathrm{mmol})$ as the $\mathrm{GC}$ internal standard, and, where indicated, $0.103 \mathrm{~g}(0.26 \mathrm{mmol})$ of Aliquat $336.5 .7 \mathrm{~mL}$ of the aqueous $\mathrm{KOH}$ solution of given concentration and $0.0455 \mathrm{~g}$ of $5 \% \mathrm{Pd} / \mathrm{C}$, or $0.0837 \mathrm{~g}$ of $5 \%$ $\mathrm{Pt} / \mathrm{C}(0.02 \mathrm{mmol}$ metal) (3\% metal to substrate ratio), or $0.25 \mathrm{~g}$ of the Raney-Ni $50 \%$ slurry $(300 \%$ metal to substrate ratio) in water were added therein. The reaction was bubbled with $\mathrm{H}_{2}$ at atmospheric pressure at $10 \mathrm{~mL} / \mathrm{min}$.

The samples were collected from the organic phase during the reaction at time intervals. The first one was taken just after the reagents had been loaded and it was considered the zero-time point. About $20 \mu \mathrm{L}$ of the reaction mixture was taken for each sample, which was then diluted with ethyl ether up to 1-2 mL. Before injection the samples were shaken with silica to remove Aliquat 336, and/or filtered to remove catalyst.

To confirm mass balance, the component concentrations have been calculated by referring their corresponding GC or GC-MS total ion peak areas to that of the internal standard, using the same calibration coefficient for products as that for the substrate, obtained from the zero-time injection. Consecutively, given no substantial mass loss (no more than 5\%), the component concentrations were normalized to the initial substrate amount $(100 \%)$ for convenience. Where graphical data plotted and/or fitted or the rate constants calculated, the Origin 6 software was used.

\section{Results and discussion}

\subsection{Reduction of p-chlorobenzaldehyde over $\mathrm{Pd} / \mathrm{C}$}

It is well known that the aldehyde group and aromatic chlorine reduce easily with hydrogen over Pd or Ni catalysts in the liquid-phase systems [31-34]. Depending on the choice of catalyst or other conditions, the reduction of carbonyl can be carried out either towards alcohols or proceed to further hydrogenolysis of the $\mathrm{C}-\mathrm{O}$ bond. The presented results show how one can choose between different products of the reduction of $p$-chlorobenzaldehyde in the multiphase reduction system, where the selectivity of the reaction is just a function of the presence of the quaternary salt, Aliquat 336.

The reaction of $p$-chlorobenzaldehyde (1) over $\mathrm{Pd} / \mathrm{C}$ in the multiphase system can proceed with different selectivity depending on the presence of the ammonium salt, Aliquat 336 , in the system. In the absence of Aliquat 336 the reaction gives selectively toluene $(\mathbf{6})(\sim 99 \%)$ in a short time $(1 \mathrm{~h})$. The intermediates, such as benzaldehyde (2), benzyl alcohol (4), and $p$-chlorobenzyl alcohol (3) are formed in the amounts not exceeding 5\% of the initial substrate concentration. Considering their profiles (Fig. 1), one can suggest

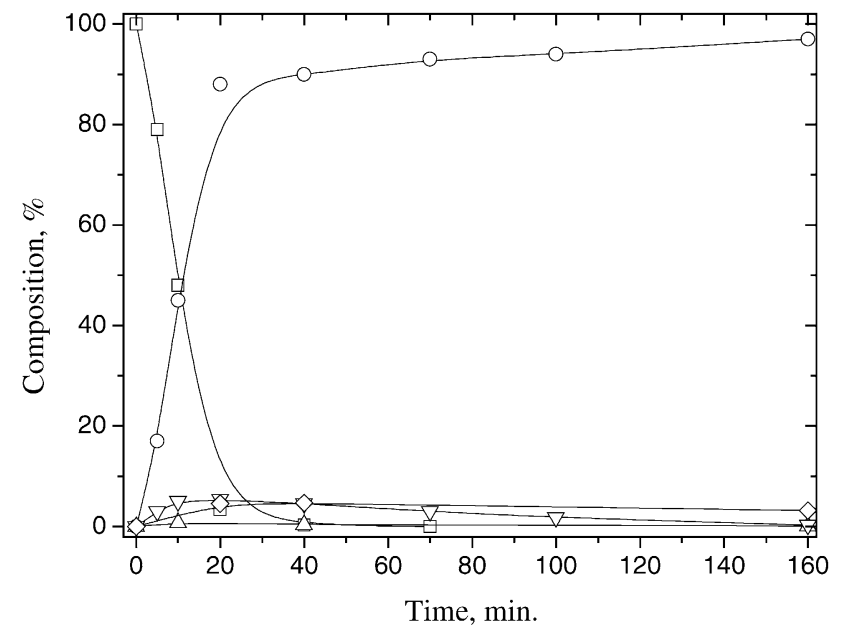

Fig. 1. Reduction of $p$-chlorobenzaldehyde $(0.7 \mathrm{mmol})$ over $5 \% \mathrm{Pd} / \mathrm{C}$ $(0.0455 \mathrm{~g})$ in isooctane-1\% aqueous $\mathrm{KOH}(10 \mathrm{~mL}: 5.7 \mathrm{~mL}) .(\square) \mathbf{1} ;(\triangle) \mathbf{2}$; $(\diamond)$ 3; $(\nabla) \mathbf{4} ;(\bigcirc) \mathbf{6}$

that $\mathbf{1}$ is converted dominatingly to $\mathbf{2}$ at the first stage, which gives then $\mathbf{4}$ and $\mathbf{6}$ (see Scheme 2), with the subsequent step being always faster then the previous one. Formation of $\mathbf{3}$ is rather a side process since 3 does not disappear from the reaction even after $2-3 \mathrm{~h}$; the ratio of $\mathbf{6}$ and $\mathbf{3}$ has been found to be $98: 2$ after $160 \mathrm{~min}$ of the reaction.

In the presence of Aliquat 336 the reaction is generally slower and gives predominantly 4 via the $\mathbf{1} \rightarrow \mathbf{2} \rightarrow \mathbf{4}$ pathway (Scheme 2). No formation of $\mathbf{3}$ has been detected. It has been reported earlier that the presence of Aliquat 336 and base normally speeds up the dechlorination step and makes it precede selectively reduction of other functionalities, in particular that of carbonyl group [25]. Hydrodechlorination of monochlorinated aromatics, however, appears fast enough even in the absence of Aliquat 336; the dechlorination step in $\mathbf{1}$ occurs with a rate similar to that

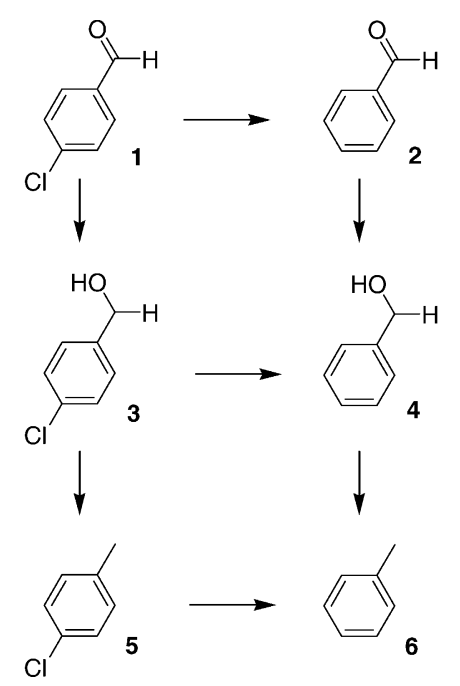

Scheme 2. Proposed reduction pathways of $p$-chlorobenzaldehyde over $\mathrm{Pd} / \mathrm{C}$. 


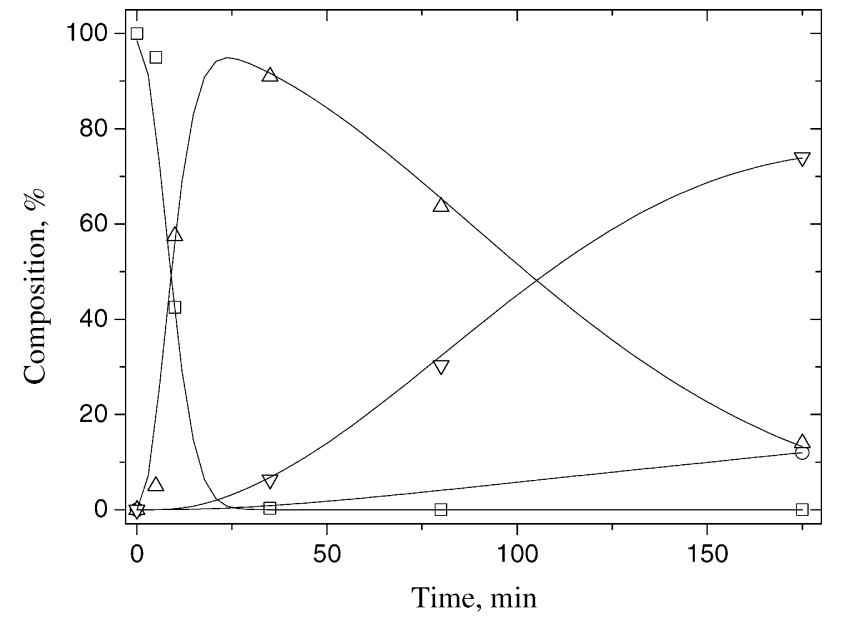

Fig. 2. Reduction of $p$-chlorobenzaldehyde $(0.7 \mathrm{mmol})$ over $5 \% \mathrm{Pd} / \mathrm{C}$ $(0.0455 \mathrm{~g})$ in isooctane- $1 \%$ aqueous $\mathrm{KOH}(10 \mathrm{~mL}: 5.7 \mathrm{~mL})$ in the presence of Aliquat $336(0.26 \mathrm{mmol})$. ( $\square) \mathbf{1} ;(\triangle) \mathbf{2} ;(\nabla) \mathbf{4} ;(\bigcirc) \mathbf{6}$.

in the absence of Aliquat 336, and gives around $90 \%$ of $\mathbf{2}$ at 20-30 min reaction time, which then undergoes a slower step of carbonyl hydrogenation to 4 (Fig. 2). Further reduction of $\mathbf{4}$ (hydroxyl group hydrogenolysis) is even slower and gives only $10 \%$ of $\mathbf{6}$ at 175 min reaction time, whilst $70 \%$ is $\mathbf{4}$ and remaining $10 \%$ is the unreacted 2 .

Therefore, the presence of Aliquat 336, though provokes selective dechlorination versus reduction of carbonyl, impedes the successive reduction of carbonyl. Similar results have been obtained earlier for the behavior of other $p$-chlorinated aromatic ketones in the same system [22-25], namely 2- and 4-bromoacetophenones, 3- and 4-chloropropiophenones, and 4,4'-dichlorobenzophenone, which yield selectively the dehalogenated product $(>95 \%)$ in the presence of Aliquat 336 using $\mathrm{Pd} / \mathrm{C}$ in the multiphase system (Scheme 3). Otherwise, if no ammonium salt is used the parent hydrocarbons are the major products $(>94 \%)$. In the present case, the reaction proceeds further, up to the corresponding alcohol, which means that the aldehyde group appears more reactive than the ketone one under the conditions studied.

We suppose that adsorption of Aliquat 336 on the catalyst surface restricts adsorption of the aromatic substrate in a flat configuration, i.e. with the coordination of the aromatic ring and the carbonyl at the same time. In this way, the reduction

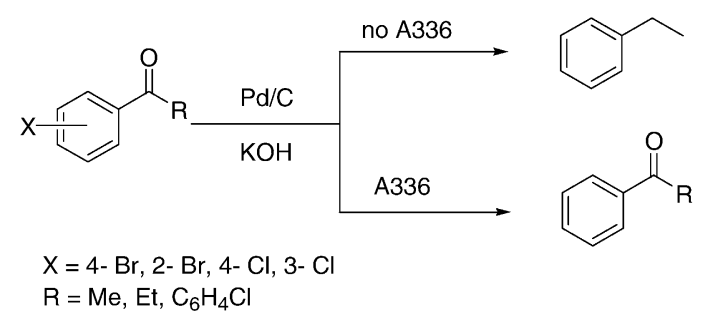

Scheme 3. Selectivity of reduction of $p$-halogenated aromatic ketones under multiphase conditions. of the latter is less favorable, while for dechlorination step the flat configuration seems not to be necessary. This is also supported by the absence of carbonyl reduction in $\mathbf{1}$ in the system with Aliquat 336, while the reduction of carbonyl occurs readily in $\mathbf{2}$ in the same reaction. Naturally, in the absence of Aliquat 336, both the reductions of carbonyl and of chlorine are possible in $\mathbf{1}$.

\subsection{Reduction of p-chlorobenzaldehyde over Pt/C}

Whereas the reduction of $p$-chlorobenzaldehyde over $\mathrm{Pd} / \mathrm{C}$ affords, first of all, hydrodechlorination, the majority of other homogeneous and heterogeneous catalytic and non-catalytic systems induce selective hydrogenation of $\mathrm{C}=\mathrm{O}$ [35-37]. Similarly, the hydrodechlorination is suppressed in the reaction of $p$-chlorobenzaldehyde over $\mathrm{Pt} / \mathrm{C}$ under the multiphase conditions studied, since $\mathrm{Pt} / \mathrm{C}$ is normally less active for removal of aromatic chlorine than $\mathrm{Pd} / \mathrm{C}$. Either with or without Aliquat 336 the first step is the reduction of the aldehyde group in $\mathbf{1}$ to give $\mathbf{3}$. The presence of Aliquat 336 also in this case brings a significant change in the reaction selectivity. The reaction in the absence of Aliquat 336 proceeds competitively via $1 \rightarrow 2 \rightarrow 4$ and $\mathbf{1} \rightarrow \mathbf{3} \rightarrow \mathbf{5} \rightarrow \mathbf{6}$ pathways (see Scheme 2), giving predominantly $\mathbf{3}$ (60\% after $100 \mathrm{~min}$ ), which then undergoes slower reduction to 5 (found in $10 \%$ in the final mixture after $3 \mathrm{~h}$ ). Another byproduct in the final mixture is 4 (around 10\%), while $\mathbf{5}$ and $\mathbf{2}$ have been formed only intermediately in the amounts not exceeding $10 \%$ and have not be found in the final mixture. The reaction profiles suggest that toluene is formed via pathway $1 \rightarrow 3 \rightarrow 5 \rightarrow 6$ and not from 4 , which is formed as a side terminal product via a parallel pathway $\mathbf{1} \rightarrow \mathbf{2} \rightarrow \mathbf{4}$ and, possibly, from $\mathbf{3}$ at the same time. Formation of cyclohexyl derivatives has not been followed, but does not exceed $20 \%$ of the total yield, as confirmed by mass balance (see Fig. 3).

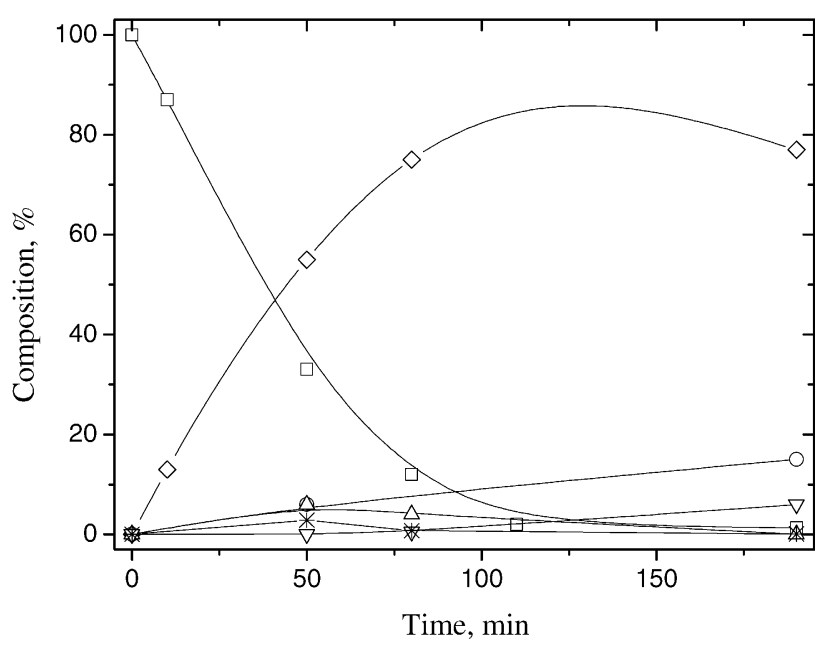

Fig. 3. Reduction of $p$-chlorobenzaldehyde $(0.7 \mathrm{mmol})$ over $5 \% \mathrm{Pt} / \mathrm{C}$ $(0.0837 \mathrm{~g})$ in isooctane-1\% aqueous $\mathrm{KOH}(10 \mathrm{~mL}: 5.7 \mathrm{~mL}) .(\square) \mathbf{1} ;(\triangle) \mathbf{2}$; $(\diamond) \mathbf{3} ;(\nabla) \mathbf{4} ;(*) \mathbf{5} ;(\bigcirc) 6$. 


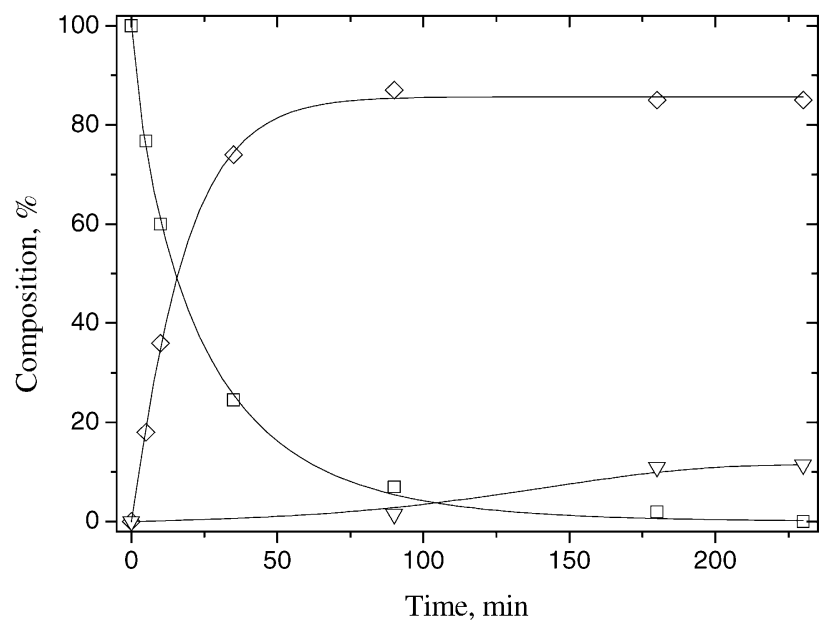

Fig. 4. Reduction of $p$-chlorobenzaldehyde $(0.7 \mathrm{mmol})$ over $5 \% \mathrm{Pt} / \mathrm{C}$ $(0.0837 \mathrm{~g})$ in isooctane- $1 \%$ aqueous $\mathrm{KOH}(10 \mathrm{~mL}: 5.7 \mathrm{~mL})$ in the presence of Aliquat $336(0.26 \mathrm{mmol}) .(\square) \mathbf{1} ;(\diamond) \mathbf{3} ;(\nabla) 4$.

The reaction of 1 in the presence of Aliquat 336 appears to be more selective and less deep; $\mathbf{3}$ is formed with the yield of $90 \%$ at $2 \mathrm{~h}$ of the reaction time (Fig. 4). Its further reduction proceeds to 4 quite slowly, affording only $10 \%$ of 4 after $4 \mathrm{~h}$. No other products and intermediates have been observed. Surprisingly, in this case the presence of Aliquat 336 plays an opposite role, i.e. impedes hydrodechlorination, whereas in most other cases it is known to accelerate it. For example, the behavior of $p$-chlorobenzaldehyde is contrary to that of $p$-chloroacetophenone and $p$-chloropropiophenone on $\mathrm{Pt} / \mathrm{C}$ $[23,25]$, which undergo hydrodechlorination at the first step in the basic system, even more selectively the presence of Aliquat 336.

\subsection{Reduction of p-chloronitrobenzene}

$p$-Chloronitrobenzene (7) is reduced selectively to aniline (10) over either $\mathrm{Pd} / \mathrm{C}$ or $\mathrm{Pt} / \mathrm{C}$ in the multiphase system. As shown in Scheme 4, the reaction can undergo two different pathways, namely $7 \rightarrow 8 \rightarrow 10$, where hydrodechlorination precedes the hydrogenation of nitro group, or $\mathbf{7} \rightarrow \mathbf{8} \rightarrow$ 10, where the reduction of nitro group, instead, precedes hydrodechlorination.

According to the corresponding kinetic profiles (see Figs. 5 and 6), these two pathways take place on $\mathrm{Pd} / \mathrm{C}$ and

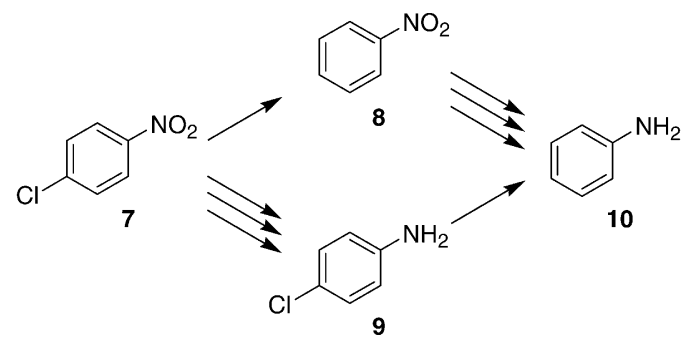

Scheme 4. General proposed reduction pathways of $p$-chloronitrobenzene.

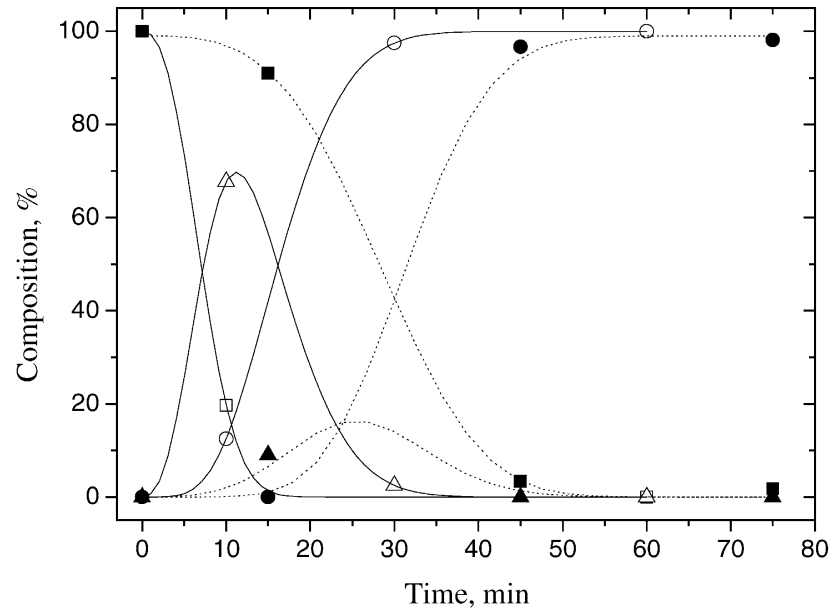

Fig. 5. Reduction of $p$-chloronitrobenzene $(0.7 \mathrm{mmol})$ over $5 \% \mathrm{Pd} / \mathrm{C}$ $(0.0455 \mathrm{~g})$ in isooctane- $1 \%$ aqueous $\mathrm{KOH}(10 \mathrm{~mL}: 5.7 \mathrm{~mL})$ in the presence (open symbols, solid lines) and in the absence (solid symbols, dash lines) of Aliquat $336(0.26 \mathrm{mmol})$. $(\boldsymbol{\square}, \square) \mathbf{7} ;(\mathbf{\Delta}, \triangle) \mathbf{8} ;(\boldsymbol{O}, \bigcirc) \mathbf{1 0}$.

$\mathrm{Pt} / \mathrm{C}$, respectively, and exclusively, i.e., as one can note from the profiles, there is only one intermediate formed in any case. The dechlorination rate of $\mathbf{7} \mathrm{on} \mathrm{Pd} / \mathrm{C}$ is identical to that of $p$-chlorobenzaldehyde (see above) and is not much different from that of the following step of nitro group hydrogenation in 8 (Fig. 5). The presence of Aliquat 336 apparently does not much affect the reaction rates; however, the reaction proceeds faster in its presence mainly due to a shorter induction period, which reaches up to $15 \mathrm{~min}$ in the reaction without Aliquat 336 (Fig. 5).

In the reaction of 7 on $\mathrm{Pt} / \mathrm{C}$, instead, the dechlorination step appears to be faster than in the analogous system with $p$-chlorobenzaldehyde (see above) and is complete in $1 \mathrm{~h}$ (Fig. 6). The reduction of nitro group, which precedes hydrodechlorination in this case, benefits from the presence of Aliquat 336. In addition, also in this case an apparent in-

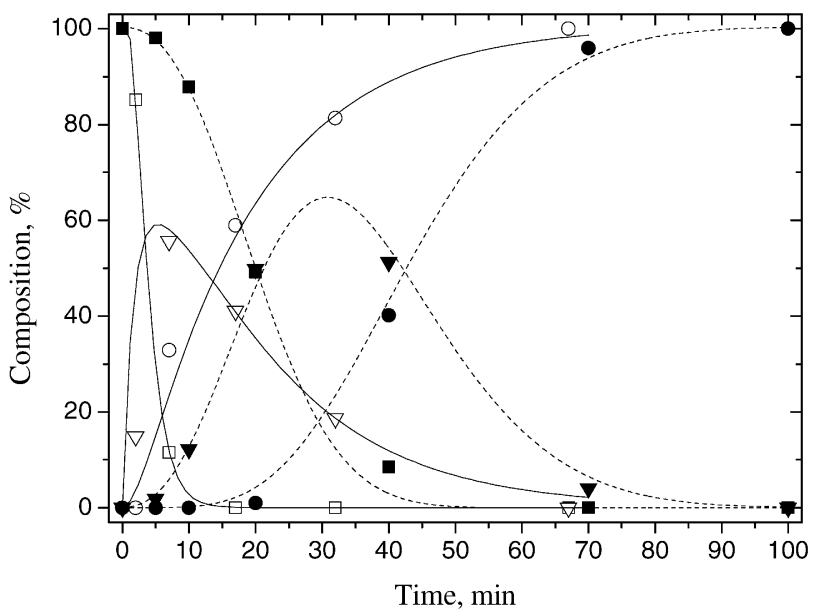

Fig. 6. Reduction of $p$-chloronitrobenzene $(0.7 \mathrm{mmol})$ over $5 \% \mathrm{Pt} / \mathrm{C}$ $(0.0837 \mathrm{~g})$ in isooctane-1\% aqueous $\mathrm{KOH}(10 \mathrm{~mL}: 5.7 \mathrm{~mL})$ in the presence (open symbols, solid lines) and in the absence (solid symbols, dash lines) of Aliquat $336(0.26 \mathrm{mmol}) .(\boldsymbol{\square}, \square) \mathbf{7} ;(\boldsymbol{\Delta}, \Delta) \mathbf{9} ;(\mathbf{O}, \bigcirc) \mathbf{1 0}$. 
<smiles>N#Cc1ccc(Cl)cc1</smiles>

11
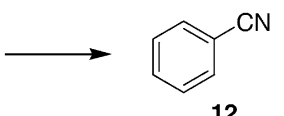

12

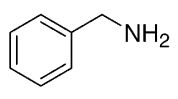

13
Scheme 5. General proposed reduction pathway of $p$-chlorobenzonitrile.

duction period is diminished in the presence of Aliquat 336 (Fig. 6).

Other known reported catalytic and non-catalytic methods for the reduction of $p$-chloronitrobenzene give usually $p$-chloroaniline (9) [38-40]. Nitrobenzene (8) can be formed in the system with sodium borohydride [41], however with low selectivity. The full reduction product, aniline, can be obtained, for example, on $\mathrm{Pd} / \mathrm{C}$ with formic acid [42].

\subsection{Reduction of p-chlorobenzonitrile over Pd/C and Pt/C}

In the reaction $p$-chlorobenzonitrile (11) hydrodechlorination is always the first reaction step that gives selectively acetonitrile (12) (Scheme 5). The dechlorination rate of $\mathbf{1 1}$ appears identical to that of $p$-chlorobenzaldehyde and $p$-chloronitrobenzene, discussed above, on either Pd or Pt; the full conversion to $\mathbf{1 2}$ is reached in nearly $30 \mathrm{~min}$ on $\mathrm{Pd} / \mathrm{C}$ and in $2 \mathrm{~h}$ on Pt/C. The reaction profiles of $\mathbf{1 1}$ on $\mathrm{Pd} / \mathrm{C}$ and $\mathrm{Pt} / \mathrm{C}$ are presented in Figs. 7 and 8, respectively. As for the previous substrates, Aliquat 336 does not seem to affect the hydrodechlorination rate.

The reduction of $\mathbf{1 1}$ gives $\mathbf{1 2}$ as the final product (no other products have been detected), with the only exception being the reaction on $\mathrm{Pd} / \mathrm{C}$ in the absence of Aliquat 336, which can proceed further to benzylamine (13). The latter is formed with a rate lower than that of hydrodechlorination, only $30 \%$ yield is obtained in $100 \mathrm{~min}$ (see Fig. 7).

The reduction of the nitrile group in benzonitrile can be carried out by a variety of methods, e.g. over Ni catalysts [43], but it usually requires harsher conditions or more so-

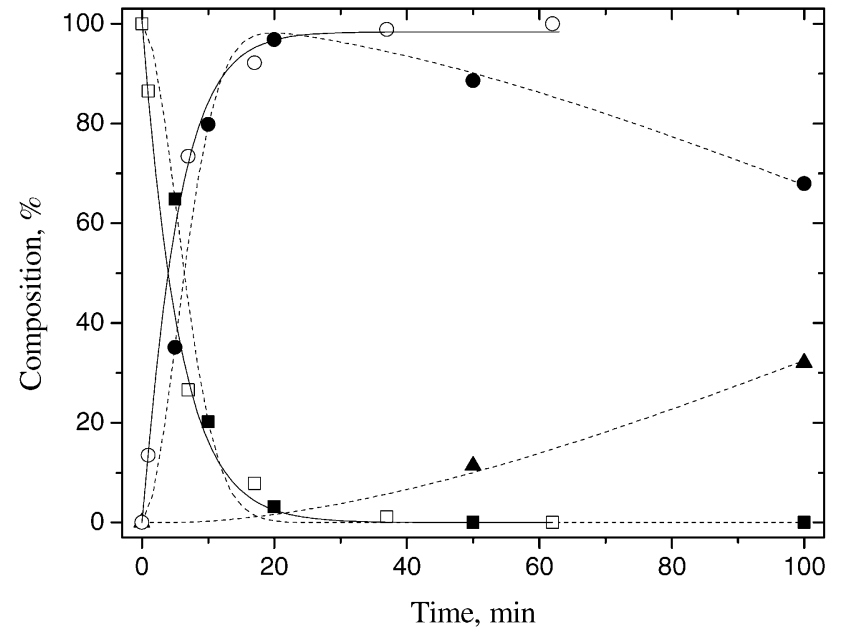

Fig. 7. Reduction of $p$-chlorobenzonitrile $(0.7 \mathrm{mmol})$ over $5 \% \mathrm{Pd} / \mathrm{C}$ $(0.0455 \mathrm{~g})$ in isooctane- $1 \%$ aqueous $\mathrm{KOH}(10 \mathrm{~mL}: 5.7 \mathrm{~mL})$ in the presence (open symbols, solid lines) and in the absence (solid symbols, dash lines) of Aliquat $336(0.26 \mathrm{mmol})$. $(\boldsymbol{\square}, \square) \mathbf{1 1} ;(\boldsymbol{O}, \bigcirc) \mathbf{1 2} ;(\mathbf{\Delta}) \mathbf{1 3}$.

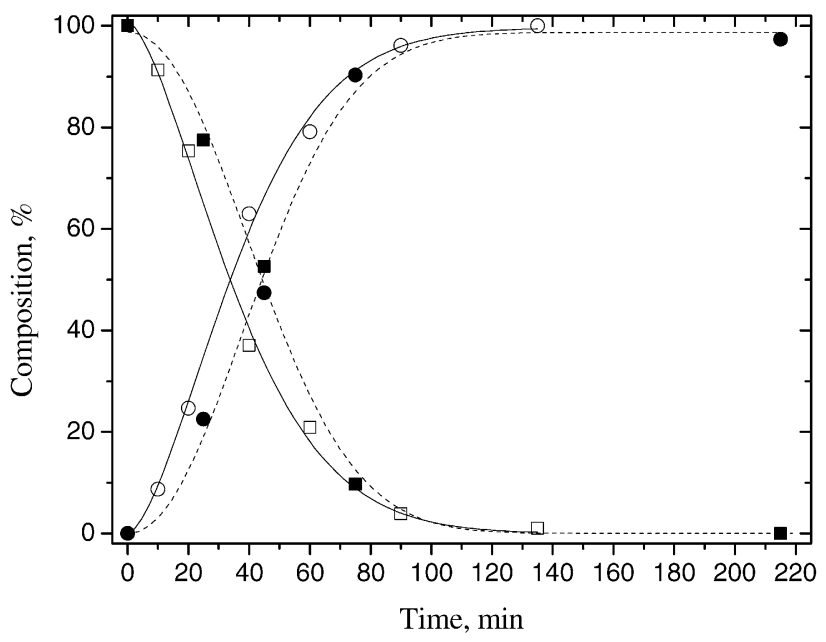

Fig. 8. Reduction of $p$-chlorobenzonitrile $(0.7 \mathrm{mmol})$ over $5 \% \mathrm{Pt} / \mathrm{C}$ $(0.0837 \mathrm{~g})$ in isooctane- $1 \%$ aqueous $\mathrm{KOH}(10 \mathrm{~mL}: 5.7 \mathrm{~mL})$ in the presence (open symbols, solid lines) and in the absence (solid symbols, dash lines) of Aliquat $336(0.26 \mathrm{mmol}) .(\mathbf{\square}, \square) \mathbf{1 1} ;(\mathbf{O}, \bigcirc) \mathbf{1 2}$.

phisticated systems. Under specific conditions (hydrazinium monoformate with Raney-Ni), the reduction of nitrile group in $p$-chlorobenzonitrile can occur even without dechlorination [44].

\subsection{Selectivity of hydrodebromination of p-bromobenzylbromide over Raney-Ni}

Aromatic versus benzyl hydrodehalogenation has been studied on the example of $p$-bromobenzylbromide (21) over Raney-Ni. In the presence of $2 \%$ aqueous $\mathrm{KOH}$ the reaction proceeds selectively via the formation of $p$-bromotoluene (22) (24 was not detected) as intermediate and gives toluene (23) in the end (entries 1 and 2 of Table 1, see also Scheme 6). In the presence of neutral aqueous phase (water) a mixture of $\mathbf{2 2}$ and $\mathbf{2 3}$ is formed (entry 3). In the acidic medium (entries 4 and 5) only the benzyl bromine if reduced giving 22 as the only reaction product.

Making comparison of the data reported in Table 1 on benzyl and aromatic hydrodebromination rates, one can see also that in all the systems studied there is a co-catalytic effect of Aliquat 336 on both the reduction of benzyl and

Table 1

Hydrodebromination of $p$-bromobenzylbromide over Raney-Ni in the multiphase system

\begin{tabular}{llllll}
\hline No. & \multicolumn{2}{l}{ System composition } & & \multicolumn{2}{l}{$\begin{array}{l}\text { First-order rate } \\
\text { constants }\left(\times 10^{3} \mathrm{~s}^{-1}\right)\end{array}$} \\
\cline { 5 - 6 } & Aliquat 336 & Aqueous phase & & $k_{1}$ & \multicolumn{2}{l}{$k_{2}$} \\
\hline & & & & \\
1 & Yes & KOH 2\% & & 0.97 & 0.152 \\
2 & No & KOH 2\% & & 0.22 & 0.04 \\
3 & Yes & $\mathrm{H}_{2} \mathrm{O}$ & & 0.1 & 0.023 \\
4 & Yes & Buffer pH 4 & & 0.73 & 0 \\
5 & No & Buffer pH 4 & 0.52 & 0 \\
\hline
\end{tabular}




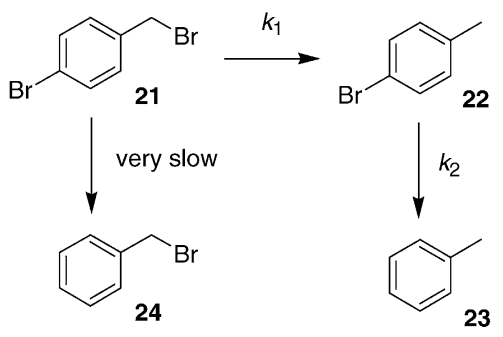

Scheme 6. Hydrodebromination pathways of $p$-bromobenzylbromide.

aromatic bromine steps, however its presence does not change much the selectivity of the reaction (see, for example, entries 1 and 2, or 4 and 5).

\section{Conclusion}

It has been demonstrated that the presence of a quaternary ammonium salt, Aliquat 336, in the biphasic catalytic reduction system with $\mathrm{Pd} / \mathrm{C}, \mathrm{Pt} / \mathrm{C}$, Raney-Ni can affect the reaction rate and selectivity in different ways. Although the true origin of the effects produced by Aliquat 336 is not completely clear, and linked probably to its adsorption on the surface, a number of evidences concerning particular effects by Aliquat 336 on the reduction pathways of several polyfunctionalized aromatics have been collected, based on the qualitative analysis of the reaction kinetics.

It has been shown, in particular, that the presence of Aliquat 336 can accelerate reduction of certain groups, e.g. of aromatic chlorine, though at the same time it can impede reduction of other functions, such as carbonyl, hydroxyl, and nitrile groups. For example, the reaction of $p$-chlorobenzaldehyde on $\mathrm{Pd} / \mathrm{C}$ can be carried out selectively to benzaldehyde or, at longer reaction times, to benzyl alcohol, which dominates over the final reduction product, toluene; the latter is the only product in the system without Aliquat 336. In the reaction of $p$-chlorobenzonitrile on $\mathrm{Pd} / \mathrm{C}$ the reduction of nitrile group, which follows dechlorination, is possible only in the absence of Aliquat 336.

In addition, the presence of Aliquat 336 affords an increase the reaction regioselectivity, e.g. in the same reduction of $p$-chlorobenzaldehyde, which can undergo the processes of either dechlorination or reduction of carbonyl group, the former is more favorable over $\mathrm{Pd} / \mathrm{C}$ and the latter over $\mathrm{Pt} / \mathrm{C}$, though still there is a small contribution of the competitive other process. The presence of Aliquat 336 removes such a contribution, i.e. makes the dechlorination step selective over $\mathrm{Pd} / \mathrm{C}$ and reduction of carbonyl group over $\mathrm{Pt} / \mathrm{C}$ (even though the influence of Aliquat 336 over each of these two processes is different, as stated above).

These considerations suggest that the presence of Aliquat 336 on the catalyst can interfere into the processes of substrate coordination on the surface, thereby restricting certain geometrical conformations, such as the flat adsorption of the aromatic ring or, instead, coordinating certain groups on the catalyst in a way that favors their reaction. Moreover, the presence of Aliquat 336 seems to create a different reaction environment, an ionic liquid in a way (Aliquat 336 is a liquid ionic salt at room temperature), which can incite a completely different reaction.

Another important issue appears to be the choice of the metal catalyst, $\mathrm{Pd} / \mathrm{C}$ or $\mathrm{Pt} / \mathrm{C}$ in our case, in defining the sequence or regioselectivity of reduction of different functions in polyfunctionalized aromatics. For example, in $p$-chlorobenzaldehyde or in $p$-chloronitrobenzene dechlorination precedes reduction of the other function over $\mathrm{Pd} / \mathrm{C}$ and vice versa over $\mathrm{Pt} / \mathrm{C}$. In connection to this, different intermediates can be formed on different catalysts, even if the final product is the same. Eventually, these products can be obtained with good yields if running the reaction for a certain time, namely $p$-chlorobenzyl alcohol on Pt/C (yield up to $90 \%$ ), instead of benzaldehyde (up to $95 \%$ ) or toluene (up to $100 \%$ ) on $\mathrm{Pd} / \mathrm{C}$ in the reaction of $p$-chlorobenzaldehyde. Similarly, in the reaction of $p$-chloronitrobenzene to aniline nitrobenzene is formed with the yield of up to $70 \%$ on $\mathrm{Pd} / \mathrm{C}$, while on $\mathrm{Pt} / \mathrm{C}$ up to $60 \%$ of $p$-chloroaniline is formed.

Aside the effects produced by Aliquat 336 on the reaction rate, regio- and chemoselectivity, another important factor appears to be the $\mathrm{pH}$ of the aqueous system. The results on the reduction of $p$-bromobenzylbromide over Raney-Ni once more affirm the important role of $\mathrm{pH}$ in determining selectivity, where the acidic media totally impedes the reduction of aromatic bromine, while the benzyl bromide reacts readily in both acidic and basic systems. The choice of $\mathrm{pH}$, therefore, affords choosing between $p$-bromotoluene and toluene as products.

\section{Acknowledgements}

We acknowledge the support from the Interuniversity Consortium INCA (http://www.unive.it/inca/)—Research plan 6 (Use of in situ and ex situ methodologies for the contaminated soil remediation), Italian Ministry of Foreign Affairs, and INTAS 2000-00710 grant. Sergei Zinovyev thanks the INTAS fellowship YSF-00-138.

\section{References}

[1] J. Frimmel, M. Zdrazil, J. Chem. Tech. Biotechnol. 63 (1995) 17.

[2] A.R. Suzdorf, S.V. Morozov, N.N. Anshits, S.I. Tsiganova, A.G. Anshits, Catal. Lett. 29 (1994) 49.

[3] F. Gioia, V. Famiglietti, F. Murena, J. Hazard. Mater. 33 (1993) 63.

[4] M. Bonnet, P. Geneste, A. Guida, D. Mampouya, J. Org. Chem. 48 (1983) 4396.

[5] R. Gopinath, K. Narashima Rao, P.S. Sai Prasad, S.S. Madhavendra, S. Narayanan, G. Vivekanadan, J. Mol. Catal. A 181 (2002) 215.

[6] D. Santoro, V. de Jong, R. Louw, Chemosphere 50 (2003) 1255.

[7] T. Okamoto, S. Oka, Bull. Chem. Soc. Jpn. 54 (1981) 1265.

[8] R.B. LaPierre, D. Wu, W.L. Kranich, A.H. Weiss, J. Catal. 52 (1978) 59. 
[9] R.B. LaPierre, L. Guczi, W.L. Kranich, A.H. Weiss, J. Catal. 52 (1978) 218.

[10] R.B. LaPierre, L. Guczi, W.L. Kranich, A.H. Weiss, J. Catal. 52 (1978) 230

[11] Y. Hashimoto, A. Ayame, Appl. Catal. A 250 (2003) 247.

[12] H. Sajiki, A. Kume, K. Hattori, K. Hirota, Tetrahedron Lett. 43 (2002) 7247.

[13] H. Sajiki, A. Kume, K. Hattori, H. Nagase, K. Hirota, Tetrahedron Lett. 43 (2002) 7251.

[14] J. Gonzalo Rodriguez, A. Lafuente, Tetrahedron Lett. 43 (2002) 9581.

[15] J. Gonzalo Rodriguez, A. Lafuente, Tetrahedron Lett. 43 (2002) 9645.

[16] M.A. Aramendia, V. Borau, I.M. Garcia, C. Jimenez, A. Marinas, J.M. Marinas, F.J. Urbano, Appl. Catal. B 43 (2003) 71.

[17] Y. Ukisu, T. Miyadera, Appl. Catal. B 40 (2003) 141.

[18] V. Simagina, V. Likholobov, G. Bergeret, M.T. Gimenez, A. Renouprez, Appl. Catal. B 40 (2003) 293.

[19] C.A. Marques, M. Selva, P. Tundo, J. Chem. Soc., Perkin Trans. 1 (1993) 529.

[20] C.A. Marques, M. Selva, P. Tundo, J. Org. Chem. 58 (1993) 5256.

[21] C.A. Marques, M. Selva, P. Tundo, J. Org. Chem. 59 (1994) 3830.

[22] C.A. Marques, M. Selva, P. Tundo, J. Org. Chem. 60 (1995) 2430.

[23] M. Selva, P. Tundo, A. Perosa, J. Org. Chem. 63 (1998) 3266.

[24] A. Perosa, M. Selva, P. Tundo, J. Org. Chem. 64 (1999) 3934.

[25] P. Tundo, S. Zinovyev, A. Perosa, J. Catal. 196 (2000) 330.

[26] C.A. Marques, O. Rogozhnikova, M. Selva, P. Tundo, J. Mol. Catal. A 96 (1995) 301.
[27] S. Zinovyev, A. Perosa, S. Yufit, P. Tundo, J. Catal. 211 (2002) 347.

[28] A. Perosa, M. Selva, P. Tundo, S.S. Zinovyev, Appl. Catal. B 32 (2001) L1.

[29] S.S. Zinovyev, N.A. Shinkova, A. Perosa, P. Tundo, J. Appl. Catal. B 47 (2004) 27-36.

[30] P. Tundo, A. Perosa, S.S. Zinovyev, J. Mol. Catal. 204-205C (2003) 747-754.

[31] L.Y. Keefer, G. Lunn, Chem. Rev. 89 (1989) 459.

[32] E. Schwenk, D. Papa, B. Whitman, H. Ginsberg, J. Org. Chem. 9 (1944) 1.

[33] E.N. Balko, E. Przybylski, F.V. Trentini, Appl. Catal. B 2 (1993) 1.

[34] M.A. Aramendia, V. Borau, C. Jiménez, J.M. Marinas, M.E. Sempere, P. Urbano, Appl. Catal. 43 (1988) 41.

[35] T. Fuchikami, Y. Ubukata, Y. Tanaka, Tetrahedron Lett. 32 (1991) 1199.

[36] W.H. Carothers, R. Adams, J. Am. Chem. Soc. 46 (1924) 1675.

[37] R.V. Shankland, M. Gomberg, J. Am. Chem. Soc. 52 (1930) 4973.

[38] F.B. Dains, W.O. Kenyon, J. Am. Chem. Soc. 53 (1931) 2357.

[39] C.F. Winans, J. Am. Chem. Soc. 61 (1939) 3564.

[40] P.S. Kumbhar, J. Sanches-Valente, J.M.M. Millet, F. Figueras, J. Catal. 191 (2000) 467.

[41] F. Rolla, J. Org. Chem. 46 (1981) 3909.

[42] P.N. Pandey, M.L. Purkayastha, Synthesis 10 (1982) 876.

[43] S. Takamizawa, N. Wakasa, T. Fuchikami, Syn. Lett. 10 (2001) 1623.

[44] S. Gowda, D.C. Gowda, Tetrahedron 58 (2002) 2211. 